\title{
NGUỒN GỐC VÀ ĐIỀU KIỆN THÀNH TẠO CỦA CORINDON TRONG ĐÁ GNEIS MỎ TRÚC LÂU, HUYỆN LỤC YÊN, TỈNH YÊN BÁI
}

\author{
NGUYẼ̃N THỊ MINH THUYÊT, NGỤY TUYÊT NHUNG, NGUYẼ̃N NGỌC KHÔI \\ E-mail: nguyen.thuyet@gmail.com \\ Khoa Địa chất - Truờng Đại học Khoa học Tự nhiên - ĐHQG Hà Nội
}

Ngày nhận bài: 28-4-2009

\section{Mở đầu}

Mỏ Trúc Lâu là một trong ba mỏ ruby, saphir chính thuộc tỉnh Yên Bái. Ở đây, corindon (ruby, saphir) được khai thác ở dạng sa khoáng từ cuối những 80 của thế kỷ trước. Một số tác giả cho rằng ruby, saphir ở đây được thành tạo trong giai đoạn khí hóa nhiệt dịch [6], biến chất trao đổi giữa dung thể magma của phức hệ Phia Bioc, phức hệ Tân Hương với các đá vây quanh giàu nhôm như các đá metapelit $[1,5]$. Một số tác giả khác nhấn mạnh vai trò của quá trình biến chất trao đổi giữa dung dịch hậu magma với các đá giàu nhôm hoặc các đá bazo trong khu vực $[3,11,12]$. Những năm gần đây, corindon đã được tìm thấy trong đá gneis ở làng Chạp, Cò Mận thuộc xã Trúc Lâu và đã được một số tác giả đề cập đến $[4,10,16]$. Bài báo trình bày kết quả nghiên cứu thành phần hóa học, thông số cơ sở $(\mathrm{a}, \mathrm{c})$, đặc điểm màu sắc, bao thể, tính phát quang, phổ hấp thụ của corindon trong đá gốc và phân tích tổ hợp khoáng vật cộng sinh, nhiệt - áp

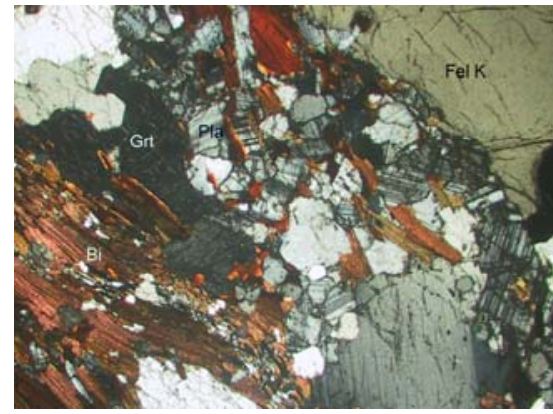

Hinh 1. Gneis biotit-granat-silimanit của hệ tầng Núi Voi. Nicon $+, d=1,2 \mathrm{~mm}$ kế địa chất nhằm xác định nguồn gốc và điều kiện thành tạo của chúng.

\section{2. Đặc điểm địa chất vùng mỏ}

Vùng mỏ đá quý Trúc Lâu nằm trong đới cấu trúc sông Hồng, thuộc các xã Trúc Lâu, Phúc Lợi, huyện Lục Yên, tỉnh Yên Bái, với phạm vi: $104^{\circ} 36^{\prime} 12^{\prime \prime}$ ' $104^{\circ} 41^{\prime} 36^{\prime \prime}$ ' kinh độ đông, 22 $01^{\circ} 40^{\prime \prime}$ " $-22^{\circ} 05^{\prime} 47^{\prime \prime}$ vỹ độ bắc và được cấu thành bởi các thành tạo biến chất của hệ tầng Núi Voi $\left(\mathrm{PR}_{1} n v\right)$, hệ tầng Ngòi Chi $\left(\mathrm{PR}_{1} n c\right)$, trầm tích Đệ tứ và đá magma xâm nhập của phức hệ Tân Hương ( $\gamma \xi \mathrm{P} t h)$.

Hệ tầng Núi Voi gồm đá gneis biotit - granat silimanit xen kẹp các thấu kính amphibolit; đá gneis biotit - granat - silimanit xen đá phiến kết tinh biotit - silimanit - granat, thấu kính gneis amphibol, amphibolit, đá hoa canciphyr có diopsit và các thể migmatit. Tại Làng Chạp và đồi Cò Mận, nam thung lũng Trúc Lâu, corindon được tìm thấy trong đá gneis của hệ tầng này $(\operatorname{hình} 1,2)$.

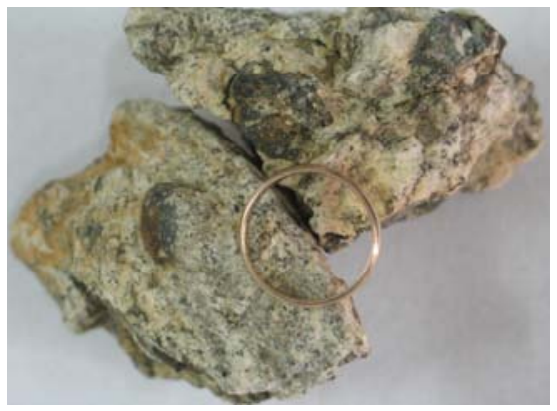

Hình 2. Gneis chứa corindon mỏ Trúc Lâu 
Nằm trên hệ tầng Núi Voi là các thành tạo của hệ tầng Ngòi Chi $(\mathrm{PR} n c)$, gồm chủ yếu là đá phiến kết tinh có thành phần thạch anh - mica ít silimanit, granat, xen các lớp mỏng đá phiến quarzit, quarzit có granat.

Các đá trầm tích biến chất trong đới Sông Hồng đã được nhiều tác giả nghiên cứu và cho rằng đạt đến $690 \pm 50^{\circ} \mathrm{C}, 0,65 \pm 0,15 \mathrm{GPa}$ [2]; $735 \pm 65^{\circ} \mathrm{C}$, $4,7 \pm 1,7 \mathrm{kbar}[15] ; 650-725^{\circ} \mathrm{C}, 7,5 \mathrm{kbar}$ [8]; $790-$ $810^{\circ} \mathrm{C}$ và $5,4-6,2$ kbar [7].

Các thành tạo trầm tích Đệ tứ phân bố chủ yếu trong các thung lũng suối phát triển kéo dài theo phương Tây Bắc - Đông Nam, phân bố trên diện tích rộng lớn trong thung lũng trung tâm xã Trúc Lâu (hình 3) và các thung lũng suối nhỏ trong vùng. Các thành tạo địa chất này chứa khá nhiều ruby, saphir và spinel.

Đá magma của phức hệ Tân Hương ( $\gamma \xi$ P th) gồm granit biotit hạt nhỏ, granosyenit, syenit lộ thành những khối nhỏ ở Cò Mận, Đồi Cây Si.

Trong vùng phát triển hệ thống đứt gãy theo phương Tây Bắc - Đông Nam.

$\rightarrow$ Hình 3. Nam thung lũng Trúc Lâu, nơi chứa corindon (ruby, saphir) sa khoáng, trên sườn đồi phát hiện tảng lăn gneis chứa corindon

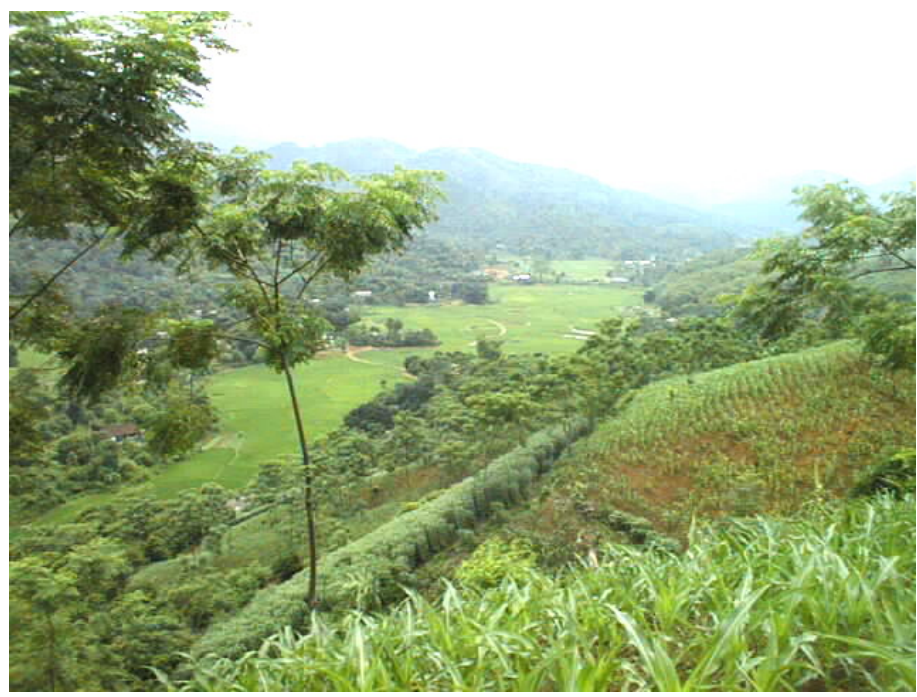

\section{Mẫu vật và phương pháp nghiên cứu}

Mẫu nghiên cứu được thu thập tại đồi Cò Mận, xã Trúc Lâu.

Corindon được tách ra khỏi đá gốc, sau đó được mài láng để xác định thành phần hóa học bằng phương pháp microzond (EPMA) tại Liên bang Nga và Đài Loan, xác định phổ hấp thụ tại Trường Đại học tổng hợp Johanes Gutenberg, Mainz, Cộng Hòa Liên Bang Đức và được nghiền thành bột để xác định thông số $\mathrm{a}, \mathrm{c}$ bằng phương pháp nhiễu xạ Rơnghen (tại trung tâm Khoa học Vật liệu, Khoa Vật lý, Trường Đại học Khoa học Tự nhiên).

Đá gneis được gia công thành lát mỏng để phân tích tổ hợp khoáng vật cộng sinh và thành phần hóa học của khoáng vật trong tổ hợp cộng sinh bằng phương pháp EPMA tại Đài Loan.

Thành phần hóa học của đá tổng được xác định bằng phương pháp huỳnh quang tia $\mathrm{X}(\mathrm{XRF})$ tại Trường Đại học Tổng hợp Greifswald, Cộng hòa Liên bang Đức.

Chương trình Barom được sử dụng để tính nhiệt độ và áp suất thành tạo.

\section{4. Đặc điểm của corindon trong đá gneis mỏ Trúc Lâu}

\subsection{Thành phần hóa học}

Corindon có công thức hóa học là $\mathrm{Al}_{2} \mathrm{O}_{3}$, nhưng chúng thường chứa nguyên tố $\mathrm{Cr}, \mathrm{Ti}, \mathrm{Fe}, \mathrm{V}, \mathrm{Ga}$, $\mathrm{Mg}$ dưới dạng thay thế đồng hình với $\mathrm{Al}$ và cũng là những nguyên tố gây màu. Trong số các nguyên tố đó, $\mathrm{Cr}, \mathrm{Fe}$ và $\mathrm{Ti}$ là ba nguyên tố phổ biến nhất.

Kết quả phân tích (bảng 1 ) cho thấy corindon trong đá gneis mỏ Trúc Lâu có hàm lượng sắt rất cao $(0,94 \%-1,33 \%$, hầu hết là trên $1 \%)$, titan có hàm lượng trung bình; một số mẫu có hàm lượng 
dưới ngưỡng đo của phương pháp $\left(10^{-5}\right)$, crôm có hàm lượng thấp $(0-0,034 \%)$. Hàm lượng sắt cao trong corindon phản ánh môi trường kết tinh của chúng rất giàu nguyên tố này.
Ngoài ba nguyên tố gây màu chính trên, corindon trong gneis Trúc Lâu còn chứa $\mathrm{Ga}, \mathrm{V}, \mathrm{Mn}$ và một số nguyên tố khác dưới dạng tạp chất như $\mathrm{Si}, \mathrm{Na}, \mathrm{K}, \ldots$ [4].

Bảng 1. Thành phần hóa học (\%TL) của corindon trong gneiss mỏ Trúc Lâu

\begin{tabular}{|c|c|c|c|c|c|c|c|c|c|c|c|}
\hline KHM & 1 & 2 & 3 & 4 & 5 & 6 & 7 & 8 & 9 & 10 & 11 \\
\hline $\mathrm{FeO}$ & 1,12 & 1,33 & 1,19 & 1,1 & 1,222 & 1,027 & 1,007 & 0,94 & 1,077 & 1,097 & 0,972 \\
\hline $\mathrm{TiO}_{2}$ & 0 & 0,012 & 0 & 0,001 & 0,01 & 0 & 0 & 0 & 0,043 & 0,023 & 0 \\
\hline $\mathrm{Cr}_{2} \mathrm{O}_{3}$ & 0,009 & 0,03 & 0,025 & 0,026 & 0,012 & 0,034 & 0,019 & 0 & 0 & 0,034 & 0,05 \\
\hline $\mathrm{Al}_{2} \mathrm{O}_{3}$ & 99,08 & 98,72 & 99,27 & 99,5 & 98,13 & 98,26 & 97,12 & 98,95 & 97,84 & 98,56 & 98,47 \\
\hline
\end{tabular}

Ghi chú: 1-4: phân tích bằng phương pháp EPMA tại Viện Hàn lâm Khoa học Nga, 5-11: Academia Sinica, Đài Loan.

\section{2. Đặc điểm cấu trúc tinh thể}

Thông số ô cơ sở của corindon Trúc Lâu được xác định dựa trên giản đồ nhiễu xạ rơnghen, các pik nhiễu xạ được dùng để tính là: $\left(\begin{array}{lll}0 & 1 & 2\end{array}\right),\left(\begin{array}{lll}1 & 0 & 4\end{array}\right)$, (1 10), (1 113$),\left(\begin{array}{lll}0 & 2 & 4\end{array}\right),\left(\begin{array}{lll}1 & 1 & 6\end{array}\right),\left(\begin{array}{lll}2 & 1 & 1\end{array}\right),\left(\begin{array}{lll}1 & 2 & 2\end{array}\right)$,

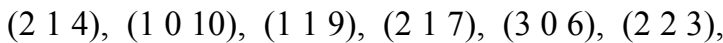
$\left(\begin{array}{lll}1 & 2 & 8\end{array}\right)$ và $\left(\begin{array}{lll}0 & 2 & 10\end{array}\right)$. Kết quả thu được là: $\mathrm{a}=4.7638$ $\pm 0.0003, \mathrm{c}=12.9934 \pm 0.0078 \mathrm{~A}^{\circ}$.

So với thông số ô cơ sở của corindon lý thuyết là $\mathrm{a}=4.758 \mathrm{~A}^{\circ} ; \mathrm{c}=12.991 \mathrm{~A}^{\circ}$, có thể thấy cấu trúc tinh thể của corindon Trúc Lâu đã giãn nở theo phương a, sự chênh lệch của thông số c không lớn, nằm trong sai số của phép đo.

Thông số a của corindon Trúc Lâu lớn hơn thông số a của corindon lý thuyết là do $\mathrm{Al}^{3+}$ trong cấu trúc tinh thể của chúng đã được thay thế đồng hình bằng các ion có bán kính lớn hơn, đặc biệt là các ion của nguyên tố sắt (bán kính $\mathrm{R}$ của $\mathrm{Al}^{3+}=$ $0,535 \mathrm{~A}^{\circ}$; của $\mathrm{Cr}^{3+}=0,615 \mathrm{~A}^{\circ}$; của $\mathrm{Fe}^{3+}=0.643 \mathrm{~A}^{\circ}$; $\left.\mathrm{Fe}^{2+}=0.78 \mathrm{~A}^{\circ} ; \mathrm{Ti}^{4+}=0.605 \mathrm{~A}^{\circ}\right)$. Đặc điểm này phù hợp với thành phần hóa học của chúng là chứa nhiều sắt.

\subsection{Màu sắc}

Corindon trong gneis mỏ Trúc Lâu chủ yếu có các màu lam tối, xám trắng, trắng đục, xám phớt vàng, trắng đục loang lổ, với cường độ rất xỉn. Loại corindon màu đỏ trong đá gốc hầu như chưa gặp, chỉ gặp một vài viên màu hồng nhạt có kích thước rất nhỏ. Giống như đặc điểm cấu trúc tinh thể, màu sắc của corindon Trúc Lâu cũng phù hợp với thành phần hóa học của chúng, bởi hàm lượng $\mathrm{Cr}$ thường nhỏ hơn $150 \mathrm{ppm}$ (hàm lượng cần thiết để corindon cho màu hồng nhạt).

\section{4. Đặc điểm bên trong}

Corindon trong gneis Trúc Lâu chứa nhiều bao thể rắn, sẫm màu, kích thước lớn, bao gồm magnetit, biotit, ilmenit (hình 4, 5). Tập hợp bao thể này phản ánh corindon đã được kết tinh trong môi trường giàu $\mathrm{Fe}$. Bên cạnh đó, trong corindon Trúc Lâu còn phát triển bao thể thứ sinh như clorit, song tinh phá hủy, nứt nẻ (hình 5,6 ).

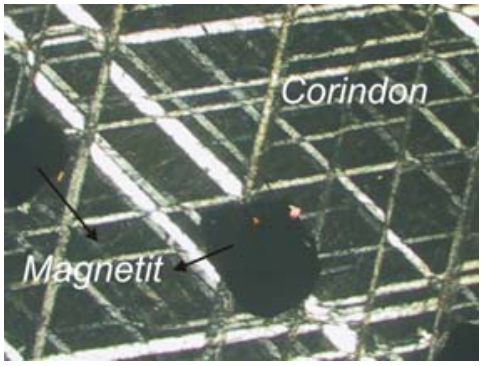

Hinh 4. Bao thể magneit, song tinh phá hủy; $\mathrm{d}=0,3 \mathrm{~mm}$, nicon: +

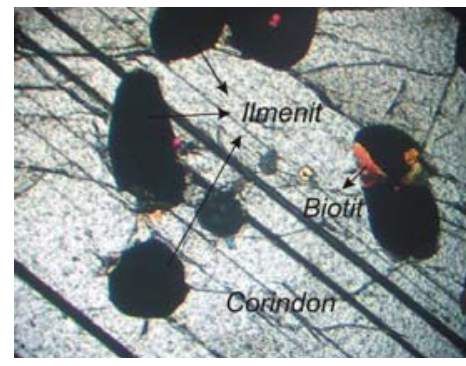

Hìn 5. Bao thể ilmenit, biotit, song tinh phá hủy; $\mathrm{d}=0,1 \mathrm{~mm}$, nicon: +

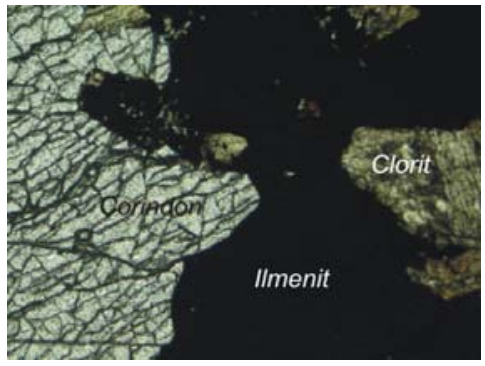

Hìn 6. Bao thể ilmenit, clorit, khe nứt; $\mathrm{d}=0,1 \mathrm{~mm}$, nicon: - 


\subsection{Tính phát quang}

Dưới tia cực tím sóng ngắn và sóng dài, hầu hết corindon trong gneis Trúc Lâu không phát quang do hàm lượng sắt quá cao đã dập hết tính phát quang.

\subsection{Phổ hấp thụ}

Phổ hấp thụ của corindon thường do các nguyên tố $\mathrm{Cr}, \mathrm{Fe}, \mathrm{V}$ tạo nên. Trong đó phổ $\mathrm{Cr}$ đặc trưng đối với corindon màu đỏ; vạch phổ thường quan sát được trong khoảng giá trị: 468,$5 ; 475,0$; 476,$5 ; 500,0 ; 610,0 ; 659,2 ; 668,0 ; 692,8 ; 694,2 \mathrm{~nm}$. Phổ hấp thụ của corindon đặc trưng bởi các nguyên tố $\mathrm{Fe}$ có giá trị vạch phổ thường trong khoảng 379,$0 ; 450,0 ; 455,0 ; 460,0 ; 471,0 \mathrm{~nm}$.

Đối với corindon trong đá gốc ở Trúc Lâu, việc quan sát phổ hấp thụ là rất khó do độ trong suốt rất thấp. Số ít viên quan sát được rõ vạch phổ hấp thụ ứng với giá trị 378 và $456 \mathrm{~nm}$ (hình 7) đặc trưng cho loại corindon chứa sắt.

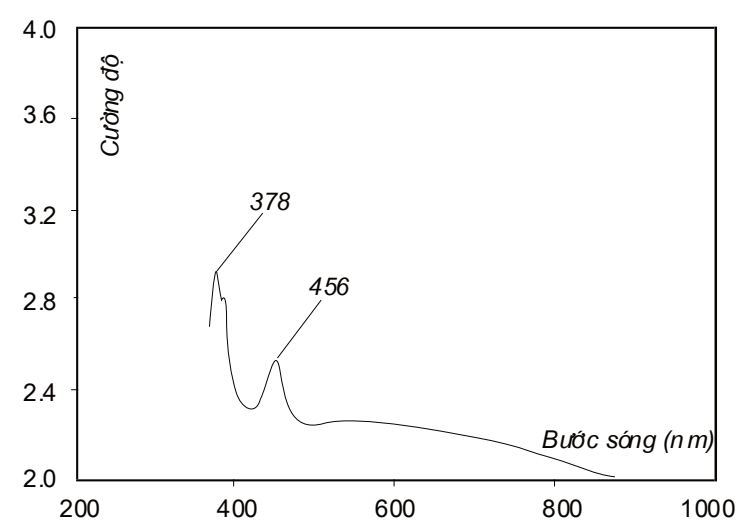

Hình 7. Phổ hấp thụ của corindon Trúc Lâu

\section{5. Đặc điểm của đá gneis Trúc Lâu}

Đá gneis chứa corindon ở Trúc Lâu (điểm lộ Cò
Mận) có kiến trúc ban biến tinh, cấu tạo phân dải, gồm chủ yếu là feldspar (chiếm $53-90 \%$ ), trong đó plagioclas chiếm $4-75 \%$, K-feldspar chiếm $<1-40 \%$, biotit từ vài phần trăm đến $40 \%$ ở loại gneis biotit. Silimanit có mặt ở tất cả các mẫu, khoảng vài phần trăm, cá biệt lên tới $21 \%$. Granat không nhiều, xuất hiện lác đác, spinel - hercynit có mặt từ vài hạt đến 6\%, khoáng vật quặng có magnetit, ilmenit. Zircon cũng xuất hiện vài hạt trong các lát mỏng, thạch anh hầu như không phát hiện thấy.

\subsection{Thành phần hóa học}

Thành phần hóa học của gneis chứa và không chứa corindon mỏ Trúc Lâu có sự khác biệt khá rõ so với đá phiến sét (bảng 2). Gneis không chứa corindon có hàm lượng silic, kali, natri trội hơn và nhôm, magie thấp hơn trong đá phiến sét. Gneis chứa corindon Trúc Lâu có hàm lượng natri, kali, đặc biệt là nhôm, sắt và titan rất cao nhưng hàm lượng magie, silic lại rất thấp so với đá phiến sét. Đặc điểm khác biệt của gneis chứa corindon phản ánh rõ các tổ hợp khoáng vật cộng sinh và thành phần của các khoáng vật trong những tổ hợp ấy (được đề cập ở phần sau).

Từ thành phần hóa học có thể xét đá sét biến chất mỏ Trúc Lâu qua sự biến đổi các tổ hợp khoáng vật của hệ hóa học KNASH và KFASH.

\subsection{Tổ hợp khoáng vật cộng sinh}

Phân tích các lát mỏng của gneis Trúc Lâu cho thấy corindon là pha nguyên sinh của đá gneis với các tổ hợp khoáng vật cộng sinh sau (hình 8-13):

- Silimanit $_{\text {dang lăng tụ }}+$ granat + spinel + corindon + biotit + K-feldspar + plagioclas

- Silimanit $_{\text {dạng lăng trụ }}+$ corindon + spinel $+\mathrm{K}-$ feldspar + plagiolas

Silimanit $_{\text {dạng lăng trụ }}+$ granat + biotit $+\mathrm{K}$-feldspar + plagioclas.

Bảng 2. So sánh thành phần các nguyên tố hóa học của gneis Trúc Lâu với hàm lượng trung bình của chúng trong đá phiến sét

\begin{tabular}{|c|c|c|c|c|c|c|c|c|}
\hline TT & $\mathrm{TiO}_{2}$ & $\mathrm{Al}_{2} \mathrm{O}_{3}$ & $\mathrm{Fe}_{2} \mathrm{O}_{3}$ & $\mathrm{MgO}$ & $\mathrm{CaO}$ & $\mathrm{Na}_{2} \mathrm{O}$ & $\mathrm{K}_{2} \mathrm{O}$ & $\mathrm{SiO}_{2}$ \\
\hline 1 & 0,061 & 13,71 & 0,61 & 0,09 & 1,2 & 3,33 & 4,97 & 73,72 \\
\hline 2 & 0,744 & 14,19 & 6,02 & 0,54 & 2,03 & 3,02 & 4,68 & 65,52 \\
\hline 3 & 4,999 & 29,62 & 19,88 & 0,25 & 0,57 & 2,03 & 5,56 & 35,79 \\
\hline 4 & 0,65 & 15,4 & 4,02 & 2,44 & 3,11 & 1,30 & 3,24 & 58,10 \\
\hline
\end{tabular}

Chú thích: 1, 2: gneis không chứa corindon; 3: gneis chứa corindon; 4: phiến sét [9]. 


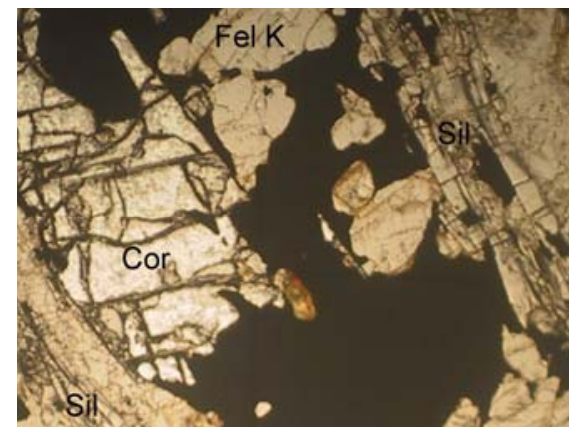

Hinh 8. THCS: Fel-K+Cor+Sil, nicon -, d = 0,6mm

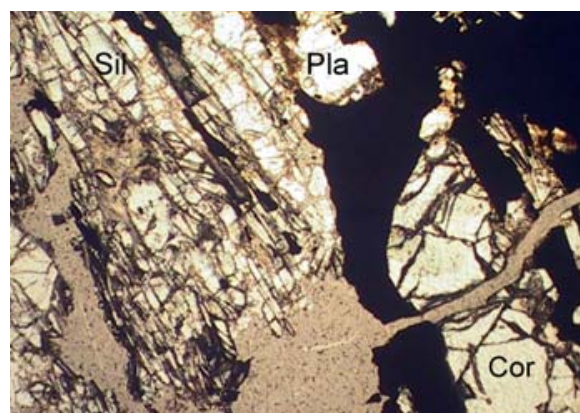

Hinh 10. THCS: Pla+Cor+Sil; nicon -, d =0,6mm

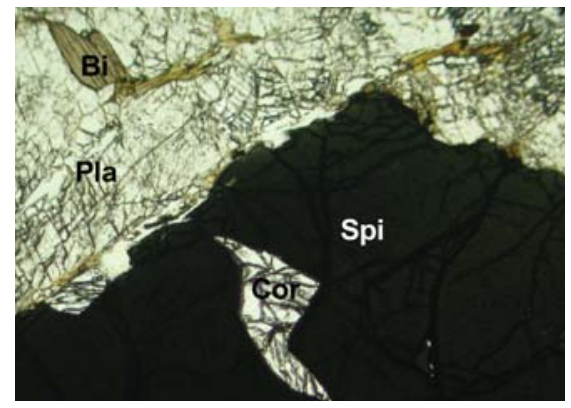

Hinh 12. THCS: Pla+Cor+Spi+Bi; nicon -,

$$
\mathrm{d}=0,6 \mathrm{~mm}
$$

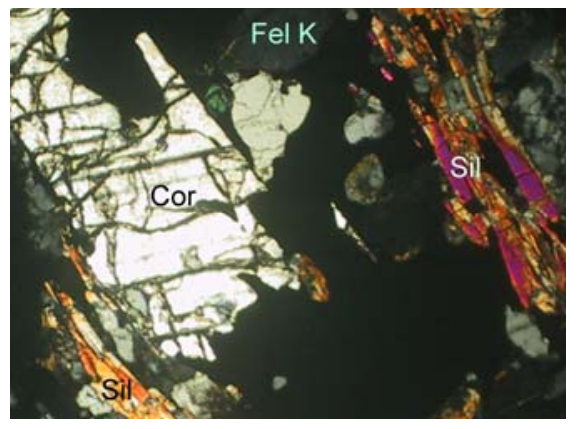

Hinh 9. THCS: Fel-K+Cor+Sil; nicon +, d = 0,6mm

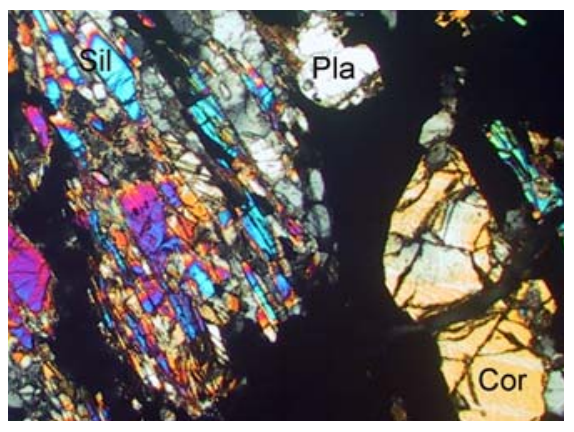

Hinh 11. THCS: Pla+Cor+Sil; nicon $+, \mathrm{d}=0,6 \mathrm{~mm}$

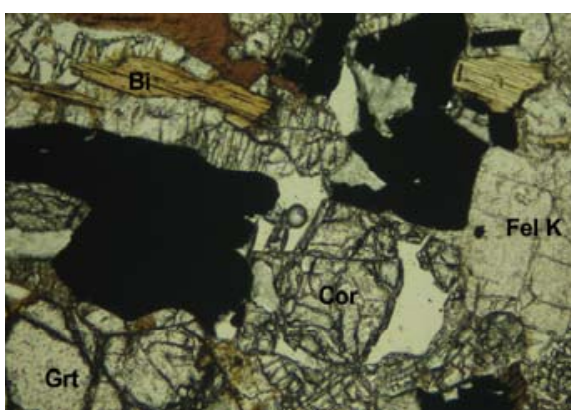

Hinh 13. THCS: Grt+Cor+Fel-K+; nicon -, $\mathrm{d}=0,6 \mathrm{~mm}$

Chú thích: Bi: biotit ; Cor: corindon; Fel-K: K-feldspar; Grt: granat; Pla: plagioclas; Sil: silimanit; Spi: spinel

\subsection{Thành phần hóa học của khoáng vật}

Thành phần hóa học của các khoáng vật được trình bày trong bảng 3,4 , qua đó có thể thấy:

- K-Feldspar : giàu kali, có chỉ số Or từ 82$86 \%$ (bảng 3 ).

- Plagiocla: là khoáng vật andezin, có chỉ sốAb từ 62-64\%1 (bảng 3).

- Granat: là khoáng vật amandin loại granat sắt, đặc trưng cho nguồn gốc biến chất khu vực.
- Biotit: loại giàu magie.

- Corindon: giàu sắt, titan màu lam loang lổ, màu xanh thẫm đến màu đen.

\section{6. Điều kiện $\mathbf{p}-\mathrm{T}$ thành tạo corindon trong đá gneis mỏ Trúc Lâu}

Điều kiện thành tạo của corindon được xác định bằng phương pháp phân tích tổ hợp khoáng vật cộng sinh và sử dụng các cặp nhiệt, áp kế địa chất. Số liệu hóa học để tính toán được trình bày trong bảng 3,4 . 
Bảng 3. Thành phần hóa học của khoáng vật K-Feldspar và Plagiocla

(Phương pháp microsond tại Viện Khoa học Trái Đất, Academia Sinica, Đài Loan)

\begin{tabular}{|c|c|c|c|c|c|c|c|c|c|}
\hline K-Feldspar & A3-1 & A3-2 & A3-3 & A3-4 & Plagiocla & A3-1 & A3-2 & A3-3 & A3-4 \\
\hline $\mathrm{SiO}_{2}$ & 64,17 & 63,15 & 63,71 & 63,55 & $\mathrm{SiO}_{2}$ & 59,43 & 58,79 & 58,11 & 58,5 \\
\hline $\mathrm{TiO}_{2}$ & 0,022 & 0,015 & 0,061 & 0,042 & $\mathrm{TiO}_{2}$ & 0,033 & 0 & 0,022 & 0,031 \\
\hline $\mathrm{Al}_{2} \mathrm{O}_{3}$ & 18,39 & 18,31 & 18,24 & 17,78 & $\mathrm{Al}_{2} \mathrm{O}_{3}$ & 24,68 & 23,55 & 24,12 & 24,07 \\
\hline $\mathrm{Cr}_{2} \mathrm{O}_{3}$ & 0,047 & 0,034 & 0,009 & 0 & $\mathrm{Cr}_{2} \mathrm{O}_{3}$ & 0 & 0,03 & 0 & 0 \\
\hline $\mathrm{FeO}$ & 0 & 0,018 & 0,098 & 0 & $\mathrm{FeO}$ & 0,014 & 0,03 & 0,031 & 0,029 \\
\hline $\mathrm{MnO}$ & 0 & 0,036 & 0 & 0 & $\mathrm{MnO}$ & 0 & 0 & 0,016 & 0 \\
\hline $\mathrm{NiO}$ & 0,022 & 0 & 0,041 & 0 & $\mathrm{NiO}$ & 0,034 & 0 & 0,016 & 0,094 \\
\hline $\mathrm{CaO}$ & 0,092 & 0,068 & 0,279 & 0,212 & $\mathrm{CaO}$ & 7,28 & 7,23 & 7,49 & 7,33 \\
\hline $\mathrm{Na}_{2} \mathrm{O}$ & 1,66 & 1,62 & 1,4 & 1,86 & $\mathrm{Na}_{2} \mathrm{O}$ & 7,35 & 7,38 & 7,28 & 7,35 \\
\hline $\mathrm{K}_{2} \mathrm{O}$ & 13,86 & 14,22 & 14,2 & 13,75 & $\mathrm{~K}_{2} \mathrm{O}$ & 0,386 & 0,357 & 0,382 & 0,302 \\
\hline $\mathrm{P}_{2} \mathrm{O}_{5}$ & 0,136 & 0,088 & 0,127 & 0,138 & $\mathrm{P}_{2} \mathrm{O}_{5}$ & 0,061 & 0,06 & 0,114 & 0,031 \\
\hline $\mathrm{ZnO}$ & 0,147 & 0,095 & 0,038 & 0,286 & $\mathrm{ZnO}$ & 0,118 & 0,087 & 0,043 & 0,064 \\
\hline An & 0,00 & 0,00 & 0,01 & 0,01 & An & 0,35 & 0,34 & 0,35 & 0,35 \\
\hline$A b$ & 0,15 & 0,15 & 0,13 & 0,17 & $A b$ & 0,63 & 0,64 & 0,62 & 0,63 \\
\hline Or & 0,84 & 0,85 & 0,86 & 0,82 & Or & 0,02 & 0,02 & 0,02 & 0,02 \\
\hline
\end{tabular}

Bảng 4. Thành phần hóa học của khoáng vật Granat và Biotit (Phương pháp microsond tại Viện Khoa học Trái Đất, Viện Hàn Lâm Sinica, Đài Loan)

\begin{tabular}{|c|c|c|c|c|c|c|c|c|c|}
\hline Granat & $3 A 3-1$ & 3АЗ-2 & 3A3-3 & $3 A 3-4$ & Biotit & $3 A 3-1$ & $3 A 3-2$ & 3A3-3 & $3 A 3-4$ \\
\hline $\mathrm{SiO}_{2}$ & 38,03 & 38,2 & 38,87 & 37,81 & $\mathrm{SiO}_{2}$ & 36,13 & 35,33 & 30,66 & 35,27 \\
\hline $\mathrm{TiO}_{2}$ & 0,017 & 0 & 0,052 & 0 & $\mathrm{TiO}_{2}$ & 4,34 & 3,83 & 6,24 & 6,48 \\
\hline $\mathrm{Al}_{2} \mathrm{O}_{3}$ & 21,86 & 21,84 & 21,86 & 21,51 & $\mathrm{Al}_{2} \mathrm{O}_{3}$ & 17,59 & 17,35 & 14 & 15,86 \\
\hline $\mathrm{Cr}_{2} \mathrm{O}_{3}$ & 0,032 & 0,026 & 0,078 & 0,019 & $\mathrm{Cr}_{2} \mathrm{O}_{3}$ & 0,139 & 0,122 & 0,17 & 0,183 \\
\hline $\mathrm{FeO}$ & 29,51 & 30,33 & 29,23 & 29,64 & $\mathrm{FeO}$ & 14,79 & 14,81 & 14,54 & 14,7 \\
\hline $\mathrm{MnO}$ & 1,53 & 1,41 & 1,249 & 1,197 & $\mathrm{MnO}$ & 0,051 & 0,016 & 0,053 & 0 \\
\hline $\mathrm{MgO}$ & 7,3 & 7,42 & 7,37 & 7,62 & $\mathrm{MgO}$ & 12,25 & 12,17 & 12,27 & 12,3 \\
\hline $\mathrm{NiO}$ & 0,049 & 0,067 & 0 & 0 & $\mathrm{CaO}$ & 0,015 & 0 & 0 & 0 \\
\hline $\mathrm{CaO}$ & 1,88 & 1,41 & 2,21 & 2,28 & $\mathrm{Na}_{2} \mathrm{O}$ & 0,153 & 0,132 & 0,16 & 0,152 \\
\hline $\mathrm{P}_{2} \mathrm{O}_{5}$ & 0,072 & 0,01 & 0,134 & 0,028 & $\mathrm{~K}_{2} \mathrm{O}$ & 9,32 & 9,46 & 9,33 & 9,22 \\
\hline $\mathrm{ZnO}$ & 0,101 & 0 & 0,058 & 0,036 & $\mathrm{P}_{2} \mathrm{O}_{5}$ & 0,038 & 0,056 & 0 & 0,068 \\
\hline Xmg & 0,28 & 0,28 & 0,28 & 0,29 & $\mathrm{ZnO}$ & 0,235 & 0,159 & 0,153 & 0,185 \\
\hline$X f e$ & 0,63 & 0,65 & 0,63 & 0,63 & Xmg & 59,58 & 59,42 & 60,06 & 59,85 \\
\hline $\mathrm{Xmn}$ & 0,03 & 0,03 & 0,03 & 0,03 & $X f e$ & 40,37 & 40,58 & 39,94 & 40,15 \\
\hline Xca & 0,05 & 0,04 & 0,06 & 0,06 & Xca & 0,05 & 0,00 & 0,00 & 0,00 \\
\hline
\end{tabular}

Pick nhiệt độ biến chất được tính toán dựa vào cặp khoáng vật granat - biotit là $724^{\circ} \mathrm{C}$ và $769^{\circ} \mathrm{C}$ $[17,20]$; dựa vào cặp $\mathrm{K}$-feldspar - plagioclas là $650^{\circ} \mathrm{C}[18]$.

Áp suất được xác định bằng GPAQ (granat; plagioclas; alumosilicat: andaluzit, silimanit, kyanit; thạch anh) là 7,6-5,9 kbar [14]; là 6,7$5,2 \mathrm{kbar}[13]$.
Trong điều kiện nhiệt độ, áp suất trên xẩy ra những phản ứng sau:

$$
\begin{gathered}
\mathrm{Ms}+\mathrm{Qz}=\mathrm{As}(\mathrm{Sil})+\mathrm{Kfs}[19] \\
\mathrm{Ms}=\mathrm{Crn}+\mathrm{Kfs}+\mathrm{H}_{2} \mathrm{O}[19]
\end{gathered}
$$

Hai phản ứng trên cho thấy sự không tồn tại đồng thời của thạch anh, muscovit và sự phá hủy của muscovit để cho tổ hợp chứa Silimanit, Kfeldspar và corindon. 
Trong lát mỏng không còn thấy kiến trúc phá hủy của thạch anh và gneis có corindon thì không có thạch anh chứng tỏ phản ứng (1) đã kết thúc. Với phản ứng số (2) có thể thấy, corindon được hình thành do sự phá hủy của khoáng vật muscovite.

Như vây, có thể cho rằng corindon mỏ Trúc Lâu được kết tinh trong điều kiện nhiệt độ: 650 $769^{\circ} \mathrm{C}$, áp suất: 7,6 - 5,2kbar do sự phá hủy khoáng vật muscovite.

\section{Kết luận}

Corindon chỉ kết tinh trong môi trường bão hòa nhôm hoặc triệt tiêu silic vì nếu có silic thì ba nguyên tố $\mathrm{Al}, \mathrm{O}$ và $\mathrm{Si}$ kết hợp với nhau để tạo ra các khoáng vật alumosilicat và silicat nhôm. Như vậy, thành phần hóa học của gneiss chứa corindon của Trúc Lâu có thể đảm bảo về điều kiện hóa học. Bên cạnh đó, các đặc điểm về thành phần hóa học, màu sắc, cấu trúc tinh thể, đặc điểm bên trong, tính phát quang và phổ hấp thụ của corindon trong gneis Trúc Lâu đều phản ánh môi trường kết tinh giàu sắt, titan, phù hợp với thành phần hóa học của đá gốc.

Nhiệt độ và áp suất thành tạo của corindon trong gneis Trúc Lâu, theo kết quả xác định bằng tổ hợp khoáng vật cộng sinh và nhiệt áp kế địa chất nằm trong khoảng $650-769^{\circ} \mathrm{C}$ và $7,6-5,2 \mathrm{kbar}$. Các giá trị này phù hợp với điều kiện biến chất của đới Sông Hồng và vì thế có thể cho rằng corindon trong gneis Trúc Lâu có nguồn gốc biến chất khu vực từ đá sét giàu nhôm, sắt, titan và nghèo silic.

Lời cảm ơn: Tập thể tác giả xin cảm ơn TS. Vũ Văn Tích, TS. Lê Thị Thu Hương về sự giúp đõ phân tích mẫu bằng phương pháp EPMA, xác định phổ hấp thụ; và xin cảm ơn đề tài QG-10-09, Đại học Quốc Gia Hà Nội đã hỗ trợ kinh phí để hoàn thành bài báo.

\section{TÀI LIẸU DÃNN}

[1] Phạm Văn Long, 1996: Kết quả nghiên cứu bước đầu về điều kiện thành tạo và nguồn gốc corindon Lục Yên. Tạp chí Địa chất, số 237, Loạt A, 71-74.

[2] Trần Ngoc Nam, 1999: Điều kiện biến chất của các đá Dãy Núi Con Voi vùng Yên Bái và lịch sử nhiệt độ-áp suất của đới trượt cắt sông Hồng.
Tạp chí Địa chất, Loạt A, số 255, 11-12/1999, 7-13.

[3] Ngụy Tuyết Nhung, 1998: Ruby, saphir và các đá bán quý vùng mỏ Lục Yên. Tạp chí Địa chất, $\mathrm{A} / 245,62-68$.

[4] Ngụy Tuyết Nhung (chủ biên), 2007: Nghiên cứu xác lập một số loại hình mỏ đá quý có giá trị công nghiệp ở Việt Nam. Báo cáo tổng kết đề tài đề tài Trọng điểm cấp Đại học Quốc Gia Hà Nội.

[5] Trần Ngoc Quân (chủ biên), 1998: Nghiên cứu xác lập các tiền đề địa chất và dấu hiệu tìm kiếm đá qúy - nửa qúy trong trầm tích biến chất cao dải bờ trái Sông Hồng. Báo cáo Đề tài. Lưu trữ Viện Khoa học Địa chất và Khoáng sản.

[6] Nguyễn Kinh Quốc và nnk 1995: Nguồn gốc, quy luật phân bố và đánh giá tiềm năng đá quý - đá kỹ thuật Việt nam. Báo cáo Đề tài KT-01-09. Lưu trữ Viện Khoa học Địa chất và Khoáng sản.

[7] Trần Tất Thắng, Trần Tuấn Anh, 2000: Những dấu hiệu về tướng granulit trong đới Sông Hồng. Tạp chí Các Khoa học về Trái Đất 22, 4, 410-419.

[8] Nguyễn Văn Thế (chủ biên), 1999: Địa chất và khoáng sản 1/50.000 tờ Yên Thế, tờ Khe Giang, nhóm Tờ Lục Yên Châu. Cục Địa chất và khoáng sản.

[9] Đặng Trung Thuận, 2005: Địa hóa học, Nhà xuất bản Đại học Quốc gia Hà Nội.

[10] Nguyễn Thị Minh Thuyết (chủ biên), 2007: Nghiên cứu đặc điểm thạch luận đá chứa corindon hai vùng mỏ Trúc Lâu và Lục Yên. Báo cáo tổng kết đề tài ĐHQG, mã số QT.07.40.

[11] Nguyễn Ngọc Truòng, Ngụy Tuyết Nhung, Nguyễn Ngoc Khôi, Phan Văn Quýnh, Hoàng Thị Tuyết, 1994: Đặc điểm tinh thể - khoáng vật học và điều kiện thành tạo của Corindon Việt Nam. Tạp chí Địa chất, A/222, 9-16.

[12] Phan Trong Trinh, Hoang Quang Vinh, Giuliani G., Leloup P.H., Lacassin R., Pham Van Long, 1999: Geodynamic role in rubi formation in the Red river shear zone and surounding area. Journal of Geology, Series B, No. 13-14/1999, pp.144-146. 
[13] Koziol, A.M. and Newton, R.C., 1988: Redetermination of the anorthite breakdown reaction and improvement of the plagioclasegarnet-Al2SiO5-quartz barometer. American Mineralogist, 73, 216-223.

[14] Koziol, A.M. and Newton, R.C., 1989: Grossular activity-composition relationships in ternary garnets determined by reversed displacedequilibrium experiments. Contributions to Mineralogy and Petrology, 103, 423-433.

[15] Leloup, P.H., Arnaud, N. \& Lacassin, R. et al, 2001: New constraints on the structure, thermochronology and timing of the Ailao ShanRed River shear zone. Journal of Geophysical Research, 106, 6683-6732.

[16] Nguy Tuyet Nhung, Nguyen Van Nam, Nguyen Ngoc Khoi, Phan Van Quynh, Nguyen Thi Minh Thuyet, $V u$ Van Tich, 2006: Characteristic of Corundum from Primary Deposit in Truc Lau
Area, Northern Vietnam. The 1st Intrenational Gem and Jewelr Conference 6-9 december 2006. Bangkok and Chanthaburi, Thailand.

[17] Perchuk, L.L., Aranovich L.Ya, Podlesskii. $K$. $K$, et al, 1985: Precambrian granulites of the Aldan shield, eastern Siberia, USSR. J Metam Geol 3: 265-310.

[18] Perchuk, L. L., 1989: P-T-fluid regimes of metamorphism and related magmatism. In: Evolution of metamorphic Belts. Blackwell Scientific Publications, Oxford, 275-292.

[19] Frank S. Spear, 1993: Metamaphic phase equilibria and pressure - temperature - time path. Book Crafters, Inc., Chelsea, Michigan, U.S.A.

[20] Thompsonp, H., 1976: Isograd patterns and pressure-temperature distributions during regional metamorphism. Contributions to Mineralogy and Petrology, 57, 277-295.

\section{SUMMARY}

Origin and forming conditions of corundums in gneiss in Truc Lau mine, Luc Yen District, Yen Bai Province

Truc Lau gem mining area, belonged to Truc Lau, Phuc Loi commune of Luc Yen district, Yen Bai province, is located in the Red River zone. Here, corundums (ruby, sapphire) have been exploited in placer since the late 80 s of the last century. In recent years, they have been found in gneiss host rock. Based on the results of chemical composition, crystal structure, inclusion, color, absorption spectrum of corundum as well as mineral assemblage analysis and thermobarometer confirmed that corundums from Truc Lau gneiss are the production of metapelite and formed by breaking down of muscovite at $650-769^{\circ} \mathrm{C}, 7.6-5.2 \mathrm{kbar}$. 